\title{
Ações em saúde mental infantil no contexto da Atenção Básica do Sistema Único de Saúde (SUS): uma revisão integrativa da literatura brasileira
}

\author{
Actions for children's mental health on Unified Health System \\ (SUS) Primary Health Care: an integrative review \\ of Brazilian literature
}

Georgius Cardoso Esswein (https://orcid.org/0000-0002-6757-1954) ${ }^{1}$

Aline Facchin Rovaris (https://orcid.org/0000-0001-8608-2112) ${ }^{2}$

Gabrielli Pohlmann Rocha (https://orcid.org/0000-0001-9976-2993) ${ }^{3}$

Daniela Centenaro Levandowski (https://orcid.org/0000-0002-6338-7287) ${ }^{4}$

${ }^{1}$ Programa de PósGraduação em Psicologia e Saúde, Universidade Federal de Ciências da Saúde de Porto Alegre (UFCSPA)

R. Sarmento Leite 245 Sala 207, Prédio 1, Centro Histórico. 90050-170 Porto Alegre RS Brasil. georgius.esswein@gmail.com

${ }^{2}$ Centro de Atenção Psicossocial II Novos

Tempos. Canoas RS Brasil. ${ }^{3}$ Residência

Multiprofissional em Saúde Mental, Universidade

Estadual de Campinas. Campinas SP Brasil.

${ }^{4}$ Programa de Pós-

Graduação em Psicologia

e Saúde, Departamento de

Psicologia, UFCSPA. Porto

Alegre RS Brasil.

\begin{abstract}
This paper aimed to characterize actions directed to children's mental health $(\mathrm{CMH})$ in Primary Health Care (PHC), based on an integrative review of Brazilian literature (20062017). The searches were carried out from LILACS, SciELO and VHL Network databases. After applying the inclusion and exclusion criteria, 13 articles were identified for analysis, which were presented in three thematic axes: 1) Characterization of the demands on $\mathrm{CMH}$ for $\mathrm{PHC}$;2) Actions and interventions on $\mathrm{CMH}$ carried out in PHC; and 3) Difficulties and propositions for the implementation of actions on CMH in PHC. The literature points, as the main actions, the identification of CMH problems and their referral to care by specialties. Some studies described specific actions of professionals such as physicians, pediatricians, and psychologists. Interventions of a local character or in partnerships with universities were also identified. The analysis of this material indicated that PHC has been considered as an important field of action in $\mathrm{CMH}$, but that nevertheless requires greater investments, especially in professional training and work organization.

Key words Mental health, Child, Primary Health Care, Review
\end{abstract}

Resumo Este estudo objetivou caracterizar as ações voltadas à saúde mental infantil (SMI) no contexto da Atenção Básica (AB), a partir de uma revisão integrativa da literatura brasileira (2006-2017). As buscas foram realizadas a partir das bases de dados LILACS, SciELO e do Portal BVS. Após a aplicação de critérios de inclusão e exclusão, identificaram-se 13 artigos para análise, que foram apresentados em três eixos temáticos: 1) Caracterização das demandas em SMI para a $A B$; 2) Ações e intervenções de SMI realizadas na $A B ;$ e 3) Dificuldades e proposições para a implementação das ações em SMI na AB. A literatura aponta, como as principais ações, a identificação de problemas de SMI e o seu encaminhamento para atendimento por especialidades. Alguns estudos descreveram ações específicas de profissionais médicos, pediatras e psicólogos. Também foram identificadas intervenções de caráter local ou em parcerias com universidades. A análise do material demonstrou a identificação da $A B$ como um importante campo de atuação em SMI, mas que, no entanto, requer maiores investimentos em termos de formação profissional e organização do trabalho.

Palavras-chave Saúde mental, Criança, Atenção Primária à Saúde, Revisão 


\section{Introdução}

Problemas de saúde mental na infância podem prejudicar o desenvolvimento infantil e frequentemente estão associados a transtornos psicossociais na vida adulta. Desta forma, a intervenção neste contexto torna-se de extrema importância e deve ser entendida enquanto fator de prevenção e promoção de saúde a longo prazo ${ }^{1-5}$. No Brasil, um longo percurso de discussões e debates, orientados pelos princípios da reforma psiquiátrica, foi necessário para a implementação das atuais políticas e diretrizes ${ }^{6}$ no âmbito da atenção à saúde mental.

Alinhado a isso, a publicação da Política Nacional de Atenção Básica de 2006 (PNAB) foi um marco que visou a revitalização da Atenção Básica $(\mathrm{AB})$ no Brasil e reafirmou a atenção primária à saúde como a principal modalidade de ação $\mathrm{e}$ atenção à saúde ${ }^{7,8}$. Atualmente, a $\mathrm{AB}$ constitui-se como base ordenadora do cuidado e se caracteriza por um conjunto de ações de âmbito individual e coletivo, que visa a promoção e proteção em saúde, prevenção de agravos, diagnóstico, tratamento, reabilitação e redução de danos, no intuito de uma atenção integral e em consonância com o contexto da população $0^{9-11}$. Dentro dessa proposta, destaca-se a proximidade da equipe de saúde com os espaços de convivência da comunidade enquanto fator positivo na abordagem à população infanto-juvenil ${ }^{8}$.

Com o objetivo de ampliar as ações da AB, no ano de 2008 foram criados os Núcleos de Apoio à Saúde da Família (NASF). Trata-se de um serviço composto por equipe multiprofissional de diferentes áreas da saúde, para atuar em parceria com a Estratégia de Saúde da Família (ESF). Especificamente para o público infanto-juvenil, as ações potencializadas pelos NASF devem incluir a realização de grupos terapêuticos, intervenções familiares e apoio aos projetos terapêuticos construídos para os indivíduos e suas famílias ${ }^{9,12}$.

Particularmente quanto à atenção em saúde mental, a Política Nacional de Saúde Mental, implementada no país entre 1990 e 2006, incentivou a criação de serviços na perspectiva da Reforma Psiquiátrica, como mencionado anteriormente, introduzindo um modelo de atenção psicossocial pautado em uma perspectiva social sobre as pessoas em sofrimento psíquico. Desta forma, implementou-se uma rede de atendimento baseado nos princípios da integralidade de ações e da intersetorialidade ${ }^{13}$.

Neste processo, em 2011 também foi instituída a Rede de Atenção Psicossocial (RAPS), com a finalidade de criação, ampliação e articulação de pontos de atenção a pessoas com sofrimento psíquico e transtornos psicossociais ${ }^{14}$. Dentre os objetivos secundários dessa Rede consta a promoção do cuidado para grupos vulneráveis, incluindo crianças, adolescentes e jovens 9 . As RAPS encontram-se organizadas a partir de diferentes componentes, tais como: Estratégia de Reabilitação Psicossocial, Estratégias de Desinstitucionalização, Atenção Hospitalar, Atenção Residencial de Caráter Transitório, Atenção de Urgência e Emergência, Atenção Psicossocial Estratégica, e AB em Saúde?.

Neste sentido, a AB passou a ocupar um importante lugar na articulação da rede de atenção à saúde mental no processo de superação do modelo anterior, de caráter asilar e medicalizante. Sendo assim, a AB, principalmente sob a forma da Estratégia de Saúde da Família (ESF) e Unidade Básica de Saúde (UBS), tem um importante papel na detecção e atenção às demandas de saúde como um todo, incluindo as demandas de saúde mental, por ser a principal porta de entrada da atenção em saúde. Desta forma, estudos sobre saúde mental infantil (SMI) neste contexto são relevantes, já que, como mencionado, dificuldades nesse âmbito interferem no desenvolvimento das potencialidades da criança em diversas áreas da vida, e que as intervenções nestes casos têm potencial preventivo ${ }^{1,2,15}$. Portanto, é importante conhecer o estado da arte das publicações científicas brasileiras sobre a temática, de maneira a contribuir para uma reflexão sobre o atual panorama da atenção à SMI. Isso se torna mais relevante ao se considerar que um recente estudo de prevalência estimou que $13,1 \%$ de crianças e adolescentes possam sofrer de algum transtorno psiquiátrico no Brasil ${ }^{16}$. Sendo assim, o presente estudo objetivou caracterizar as ações em SMI no contexto da $\mathrm{AB}$, com base na revisão de artigos brasileiros publicados entre 2006, ano da publicação da PNAB, e dezembro de 2017.

\section{Método}

Trata-se de uma revisão integrativa da literatura, método que proporciona a síntese do conhecimento de múltiplos estudos sobre determinado assunto ${ }^{17-19}$. De fato, dentre os métodos de revisão, a integrativa é a mais abrangente, por permitir a inclusão de estudos experimentais e não-experimentais e, com isso, oferecer uma compreensão mais completa e abrangente sobre o fenômeno estudado ${ }^{17,19}$. Além disso, para o campo da saúde, 
esse tipo de revisão traz importantes contribuições para a Prática Baseada em Evidências, já que a proposta de sistematização e ordenamento contribui para um aprofundamento da compreensão sobre o tema investigado, o que pode repercutir na prática em saúde ${ }^{17}$.

A presente revisão integrativa foi elaborada seguindo diretrizes ${ }^{17,19}$ que englobam seis etapas: 1) Elaboração da pergunta norteadora, momento em que o pesquisador elabora uma hipótese ou questão de pesquisa, de forma clara, específica e relevante para o campo da saúde; 2) Busca ou amostragem na literatura, quando, considerando a questão de pesquisa, são estabelecidos critérios e o processo de seleção dos artigos para análise; 3) Definição das informações/coleta de dados, etapa em que se define as informações que serão extraídas, sintetizando-se a partir de um instrumento (no caso do presente estudo, um protocolo elaborado pelos autores, contendo informaçõeschave a serem coletadas nos artigos analisados); 4) Avaliação/Análise crítica dos estudos, quando se realiza a análise crítica dos estudos, considerando seu o rigor e características, além da classificação de evidências (no presente estudo, tal classificação baseou-se na hierarquia de evidências descrita em Souza et al. ${ }^{19}$ ); 5) Discussão/interpretação dos resultados, etapa na qual se realiza a síntese e a discussão dos principais resultados, contemplando uma comparação com o conhecimento teórico; e 6) Apresentação da revisão, que culmina na elaboração do documento que descreve todas as etapas, com o melhor detalhamento possível, e evidencia os principais achados.

Nessa revisão, a busca e a seleção dos artigos foram feitas em janeiro de 2018, a partir de consulta às bases de dados LILACS (Literatura Latino -Americana e do Caribe em Ciências da Saúde), SciELO (Scientific Electronic Library Online) e ao Portal da BVS (Biblioteca Virtual em Saúde), a partir de combinações de descritores registrados nos Descritores em Ciências da Saúde (DeCS). As fontes foram escolhidas por serem aquelas em que a grande maioria dos artigos brasileiros estão disponíveis, uma vez que se buscava literatura que retratasse a realidade do sistema de assistência à SMI no país. No Portal BVS, que comporta diversas bases, utilizou-se ainda como filtros: data de publicação (2006-2017), disponibilidade de acesso, idiomas (português) e tipo de publicação (artigo).

Posteriormente, visando ampliar o número de registros para melhor caracterizar a literatura da área, realizou-se novas buscas no Portal BVS a partir de descritores não registrados no DeCS. Para a adoção dessa estratégia, considerou-se também o fato de que buscas informais, realizadas em momento anterior à seleção dos artigos, haviam indicado a existência de outras publicações pertinentes à temática, que não haviam sido localizadas pelo emprego exclusivo de descritores indexados. No Quadro 1 encontram-se os descritores utilizados nas diferentes buscas.

Os registros localizados na primeira busca foram selecionados a partir dos seguintes critérios de inclusão: tipo de material, considerando somente artigos; ano de publicação (2006-2017); e local de realização da pesquisa (Brasil). Os registros duplicados e que não se enquadravam nos critérios de inclusão foram excluídos da análise. Após, procedeu-se a uma análise dos temas a partir da leitura de títulos e resumos. Nesta etapa, aplicou-se como critério de inclusão o foco do estudo em ações em SMI no âmbito da $A B$, desconsiderando aqueles que apenas realizavam sua coleta de dados neste contexto. Com a aplicação desse critério temático, selecionou-se 14 artigos para leitura completa. A partir dessa leitura, desses artigos, seis ainda foram excluídos, considerando como critérios de exclusão não contemplar a saúde mental exclusivamente na infância e não contemplar somente o contexto da AB. Todo esse processo de seleção está apresentado na Figura 1.

A seleção dos registros encontrados a partir do uso dos descritores não indexados no DeCS seguiu os mesmos passos descritos anteriormente, como consta na Figura 2. Esta nova busca identificou 12 artigos para análise. Contudo, após a exclusão dos registros duplicados, considerando os artigos selecionados a partir da primeira busca, feita com descritores indexados, restaram apenas 5 artigos para análise. Somando-se a estes cinco artigos os oito selecionados a partir da primeira busca, contou-se com um total de 13 artigos para análise.

Considerando os artigos selecionados para análise na primeira busca (realizada com descritores indexados) através do portal BVS, constata-se que os mesmos estavam indexados, considerando as suas repetições, nas seguintes bases: LILACS, Medline, CidSaúde, Index Psi e BDENF. Já quanto aos artigos selecionados na segunda busca, realizada com descritores não indexados no DeCS, observa-se que se encontravam indexados nas bases Index Psi, LILACS e BDENF.

Todas as consultas, seleções e exclusões dos registros foram realizadas por dois juízes, autores do artigo, de forma simultânea e independente. Nas situações de discordância, consultou-se um terceiro juiz (também autor) para a tomada de decisão. 
Quadro 1. Descritores utilizados para as buscas dos artigos e número de registros encontrados.

\begin{tabular}{|c|c|c|}
\hline \multirow{2}{*}{ Descritores } & \multicolumn{2}{|c|}{ No de registros encontrados } \\
\hline & LILACS & SciELO \\
\hline Atenção primária à saúde AND Saúde da criança AND Saúde mental & 02 & 14 \\
\hline Primary health care AND Child health AND Mental health & 02 & 66 \\
\hline Saúde mental AND Criança AND Atenção primária à saúde & 30 & 14 \\
\hline Mental health AND Child AND Primary health care & 26 & 66 \\
\hline Saúde mental AND Pré-escolar AND Atenção primária à saúde & 03 & 01 \\
\hline Mental health AND Child, preschool AND Primary health care & 02 & 02 \\
\hline Serviços de saúde mental AND Criança AND Atenção primária à saúde & 12 & 05 \\
\hline Mental health service AND Child AND Primary Health Care & 08 & 04 \\
\hline Total & 85 & 172 \\
\hline Descritores & \multicolumn{2}{|c|}{ Portal BVS } \\
\hline Atenção primária à saúde AND Saúde da criança AND Saúde mental & \multicolumn{2}{|c|}{65} \\
\hline Saúde mental AND criança AND atenção primária à saúde & \multicolumn{2}{|c|}{65} \\
\hline Saúde mental AND pré-escolar AND Atenção primária à saúde & \multicolumn{2}{|c|}{12} \\
\hline Serviços de saúde mental AND criança AND atenção primária à saúde & \multicolumn{2}{|c|}{37} \\
\hline Total & \multicolumn{2}{|c|}{179} \\
\hline Descritores (não indexados) & \multicolumn{2}{|c|}{ Portal BVS } \\
\hline Saúde mental infantil AND Atenção básica & \multicolumn{2}{|c|}{27} \\
\hline Infância AND Atenção básica AND Saúde mental & \multicolumn{2}{|c|}{12} \\
\hline Infância AND Atenção primária à saúde AND Saúde mental & \multicolumn{2}{|c|}{18} \\
\hline Saúde mental infantil AND Atenção primária à saúde & \multicolumn{2}{|c|}{28} \\
\hline Serviços de saúde mental AND Criança AND Atenção básica & \multicolumn{2}{|c|}{33} \\
\hline Saúde da criança AND Saúde mental AND Atenção básica & \multicolumn{2}{|c|}{58} \\
\hline Saúde mental AND Criança AND Atenção básica & \multicolumn{2}{|c|}{58} \\
\hline Saúde mental AND Pré-escolar AND Atenção básica & \multicolumn{2}{|c|}{13} \\
\hline Total & \multicolumn{2}{|c|}{247} \\
\hline
\end{tabular}

Fonte: Elaborado pelos autores.

Para a análise dos 13 artigos incluídos nessa revisão, foi criado um protocolo com indicadores descritivos a partir de três eixos temáticos: 1) Caracterização das demandas em SMI para a AB; 2) Ações e intervenções de SMI realizadas na AB; e 3 ) Dificuldades e proposições para a implementação das ações em SMI na AB. Esses eixos emergiram a partir da leitura integral dos 13 artigos.

\section{Resultados}

No Quadro 2 estão detalhadas as informações sobre ano de publicação, objetivos e enfoque metodológico dos artigos analisados. Percebe-se, a partir do ano de 2012, um aumento de publicações sobre a temática, pois $70 \%(\mathrm{n}=9)$ dos artigos analisados foram publicados entre 2012 e 2017. Destacaram-se, como objetivos mais frequentes, a descrição e a avaliação de estratégias de cuidado em SMI, a percepção dos profissionais sobre as ações em SMI, bem como a caracterização da população atendida. Já quanto ao enfoque metodológico, 10 artigos (77\%) eram empíricos, dois $(15,5 \%)$ eram relatos de experiência e de caso, e apenas um deles $(7,5 \%)$ apresentou um cunho teórico. A maioria dos estudos empíricos teve enfoque qualitativo $(n=5,50 \%)$, seguido de quantitativo $(n=3,30 \%)$ e misto $(n=2,20 \%)$.

O Quadro 3 apresenta detalhadamente as características metodológicas dos artigos analisados. Dentre os estudos empíricos $(n=10)$, identificaram-se como participantes: crianças $(n=6$, $60 \%)$, pais ou familiares $(n=6,60 \%)$ e profissionais de saúde $(n=6,60 \%)$. Importante considerar que $6(60 \%)$ estudos acessaram mais de um destes grupos (por exemplo, pais e profissionais, pais e crianças). Dentre os estudos que incluíam as crianças atendidas pelos serviços de saúde, identifica-se que em três $(50 \%)$ deles os dados eram provenientes de prontuários e, em cinco (83\%), também de informações referidas ou ins- 


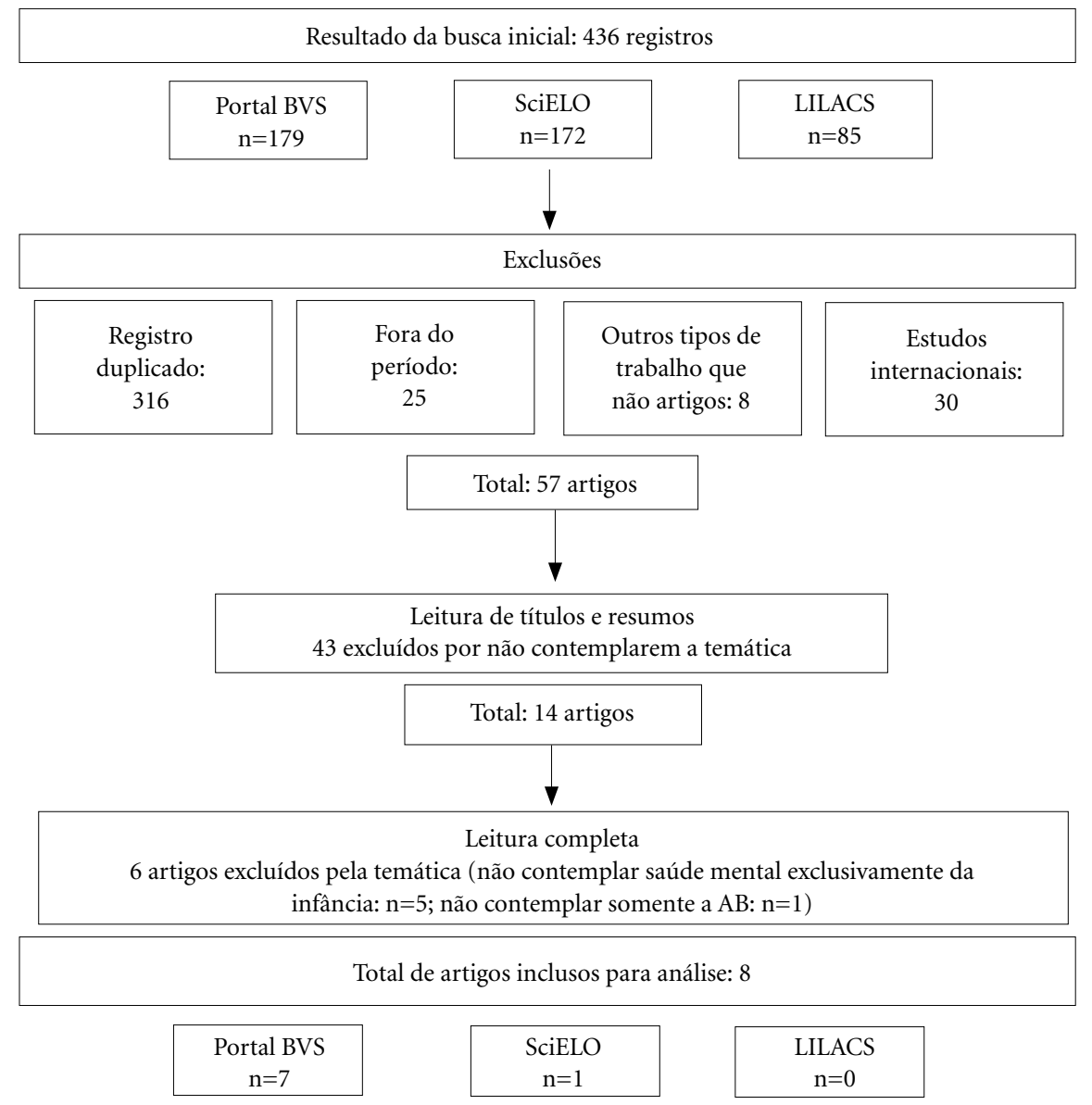

Figura 1. Fluxograma do processo de busca e seleção dos artigos com descritores indexados.

Fonte: Elaborado pelos autores.

trumentos preenchidos por familiares. Dentre a faixa etária das crianças, cinco estudos $(83 \%)$ tiveram como alvo o período de 5 a 12 anos de idade. Apenas dois estudos empíricos e um relato de experiência abrangeram crianças de faixa etária inferior. Ainda, um estudo empírico contou com crianças de um a nove anos, divididas em dois grupos etários.

Quanto aos instrumentos empregados nos estudos empíricos, verificou-se uma diversidade de estratégias para a coleta de dados, incluindo entrevistas $(n=6,60 \%)$, instrumentos padronizados para a identificação de sintomas $(n=4,40 \%)$ e a caracterização do contexto familiar $(n=2,20 \%)$, questionários $(\mathrm{n}=3,30 \%)$, consulta a dados de prontuários $(n=3,30 \%)$, diário de campo $(n=1$, $10 \%)$ e fotografias $(\mathrm{n}=1,10 \%)$. Já no que se refere à análise de dados, foram utilizados, como mé- todos qualitativos, a análise temática $(\mathrm{n}=5,50 \%)$, socio-histórica, $(\mathrm{n}=1,10 \%)$, hermenêutica fenomenológica $(n=1,10 \%)$ e o ecomapa $(n=1,10 \%)$. Dentre os métodos quantitativos, identificou-se análises estatísticas descritivas ( $\mathrm{n}=5,50 \%)$, comparativas $(n=3,30 \%)$, correlacionais $(n=1,10 \%)$ e uso de regressão uni e multivariada $(n=1,10 \%)$.

O Quadro 3 apresenta a avaliação crítica dos estudos que buscou identificar a adequada descrição dos participantes e a adequação do método empregado em relação aos objetivos propostos em cada estudo, além da validade das evidências ${ }^{19}$, sobretudo relacionadas aos resultados discutidos neste artigo. Os parâmetros utilizados para análise dos níveis de evidência foram descritos em Souza et al. ${ }^{19}$, considerando: Nível 1 (evidência resultantes de meta-análise), Nível 2 (evidências resultantes de estudos de delinea- 


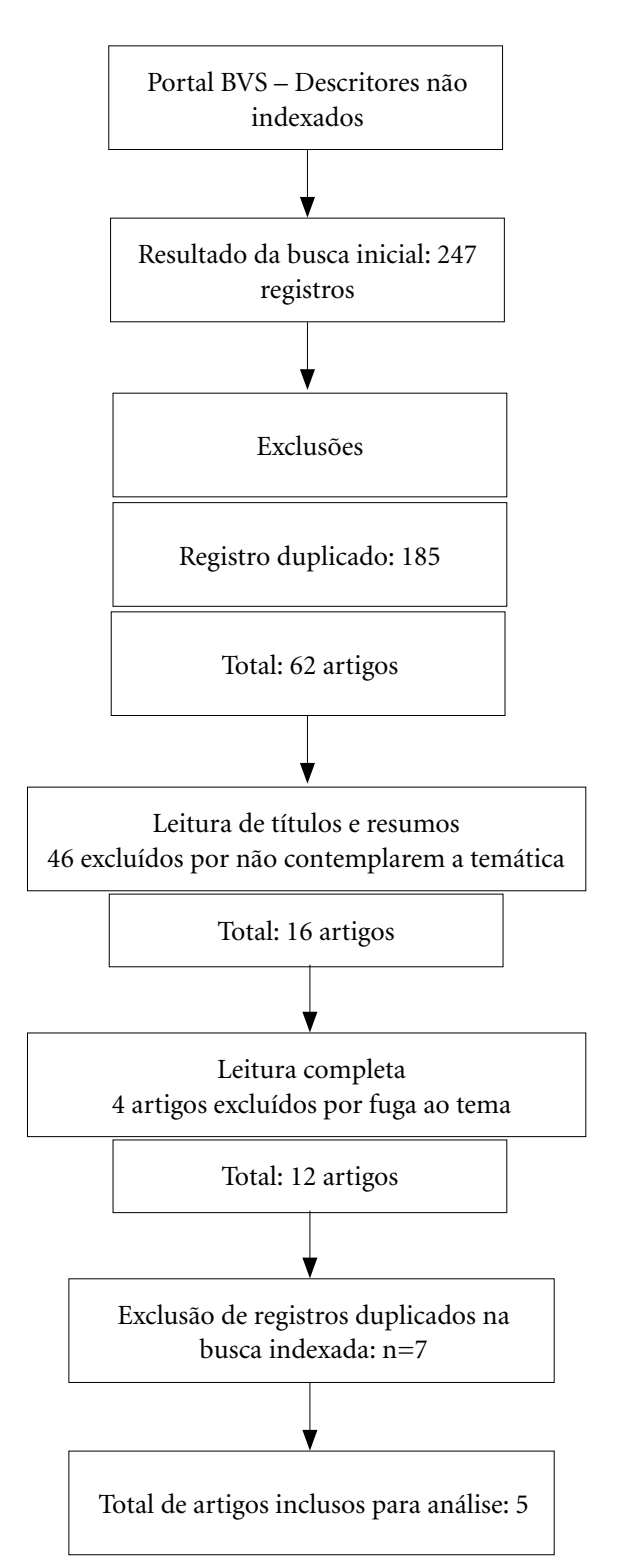

Figura 2. Fluxograma de busca e seleção de artigos com descritores não indexados.

Fonte: Elaborado pelos autores.

mento experimental), Nível 3 (evidência resultantes de estudos quase-experimentais), Nível 4 (Evidência de estudos descritivos ou de abordagem qualitativa), Nível 5 (evidências resultantes de relatos de caso ou experiência), e Nível 6 (evidência decorrente de opinião de especialistas). Dentre os 13 artigos analisados, observou-se predominância do Nível 4 de evidências, pelo maior número de estudos qualitativos identificados na literatura da área, e adequação nas descrições metodológicas.

A seguir são apresentados os principais resultados dos estudos analisados, a partir da integração das informações constantes em cada um dos eixos temáticos do protocolo descritivo elaborado para o registro das informações no presente estudo.

\section{Caracterização das demandas em SMI para a $\mathrm{AB}$}

Oito dos 13 artigos analisados referiram-se a esse eixo temático. Alguns artigos caracterizaram tais demandas a partir de dados de prevalência. No estudo de Ferriolli et al. ${ }^{2}$, das 100 crianças de Ribeirão Preto avaliadas (6 a 12 anos), 31 foram classificadas em condição de risco para transtornos emocionais/comportamentais. Sintomas de ansiedade e depressão foram os mais frequentes (39\%) e os problemas de saúde mental estavam associados, predominantemente, à instabilidade financeira e estresse materno. Já Santos e Celer ${ }^{15}$, a partir de uma amostra de 40 crianças de uma cidade do interior de São Paulo (30 a 50 meses de vida), identificaram, em mais da metade delas, risco para o desenvolvimento de problemas de saúde mental.

Um levantamento de 104 prontuários de atendimentos efetuados por psicólogos em sete UBS de São Paulo, realizado por Braga e Morais ${ }^{20}$, apontou que $76,9 \%$ das crianças atendidas apresentavam queixas escolares. Constatou também que 51,9\% destas queixas decorriam de encaminhamentos feitos pelas escolas. Outros estudos também identificaram demandas em SMI na AB decorrentes de encaminhamentos realizados por escolas ou relacionados às queixas escolares ${ }^{6,20-23}$. Em relação a isso, nota-se uma falta de consenso na literatura sobre a real demanda desses encaminhamentos ${ }^{6,23}$.

Ainda, alguns estudos caracterizaram as demandas em SMI para a $\mathrm{AB}$ a partir da visão de médicos e pediatras ${ }^{21,23,24}$. Para estes, a demanda, muitas vezes, já vem formulada pela família, e geralmente envolve suspeitas de doenças de origem orgânica e está atrelada à expectativa de intervenções medicamentosas ou encaminhamentos ${ }^{23,24}$. As demandas também são percebidas como associadas a outros contextos, tais como escola, situação familiar ou problemas socioeconômicos ${ }^{21}$.

\section{Ações e intervenções de SMI realizadas na $\mathrm{AB}$}

Diversos estudos ( $\mathrm{n}=12$ artigos) tiveram como foco a descrição de ações e intervenções em 
Quadro 2. Caracterização dos artigos analisados conforme ano, objetivo e enfoque metodológico ( $\mathrm{n}=13$ ).

\begin{tabular}{|c|c|c|}
\hline Autores/ano & Objetivo & $\begin{array}{l}\text { Tipo de estudo/ } \\
\text { Enfoque } \\
\text { metodológico }\end{array}$ \\
\hline $\begin{array}{l}\text { Tanaka e } \\
\text { Lauridsen- } \\
\text { Ribeiro }^{24}(2006)\end{array}$ & $\begin{array}{l}\text { Avaliar como os problemas de saúde mental são abordados pelos médicos } \\
\text { da } \mathrm{AB} \text { no atendimento das crianças. }\end{array}$ & Empírico/Misto \\
\hline $\begin{array}{l}\text { Braga e } \\
\text { Morais }^{20}(2007)\end{array}$ & $\begin{array}{l}\text { Discutir se as recentes políticas educacionais e de saúde e se os estudos a } \\
\text { respeito da demanda escolar em clínicas-escola e em serviços públicos de } \\
\text { saúde têm surtido efeito e provocado mudanças significativas na prática } \\
\text { dos psicólogos das Unidades Básicas de Saúde (UBS). }\end{array}$ & $\begin{array}{l}\text { Empírico/ } \\
\text { Quantitativo }\end{array}$ \\
\hline $\begin{array}{l}\text { Ferriolli et al. }{ }^{2} \\
(2007)\end{array}$ & $\begin{array}{l}\text { Analisar a associação entre variáveis do contexto familiar e o risco de } \\
\text { problemas emocionais/comportamentais em crianças cadastradas em } \\
\text { Programa Saúde da Família (PSF). }\end{array}$ & $\begin{array}{l}\text { Empírico/ } \\
\text { Quantitativo }\end{array}$ \\
\hline $\begin{array}{l}\text { Tanaka e } \\
\text { Lauridsen- } \\
\text { Ribeiro }^{21}(2009)\end{array}$ & $\begin{array}{l}\text { Investigar a abordagem dos programas de saúde mental (PSM) durante } \\
\text { atendimento na } \mathrm{AB} \text {. }\end{array}$ & Empírico/Misto \\
\hline $\begin{array}{l}\text { Cavalcante et } \\
\text { al. }^{25}(2012)\end{array}$ & $\begin{array}{l}\text { Compreender como tem se dado o uso do apoio matricial como } \\
\text { ferramenta do cuidado à criança com problema de saúde mental na } \\
\text { Estratégia de Saúde da Família (ESF). }\end{array}$ & $\begin{array}{l}\text { Empírico/ } \\
\text { Qualitativo }\end{array}$ \\
\hline $\begin{array}{l}\text { Carvalho et al. }{ }^{5} \\
\text { (2013) }\end{array}$ & $\begin{array}{l}\text { Conhecer as concepções dos profissionais da ESF sobre a Intervenção } \\
\text { Precoce (IP) e em que medida eles utilizavam tais concepções em suas } \\
\text { práticas profissionais. }\end{array}$ & $\begin{array}{l}\text { Empírico/ } \\
\text { Qualitativo }\end{array}$ \\
\hline $\begin{array}{l}\text { Sinibaldi }{ }^{6} \\
(2013)\end{array}$ & $\begin{array}{l}\text { Problematizar como tem sido construída a relação entre os serviços de } \\
\text { Atenção Primária (AP) e os cuidados dispensados à infância no Brasil. }\end{array}$ & Teórico \\
\hline $\begin{array}{l}\text { Becker et al. }{ }^{22} \\
(2014)\end{array}$ & $\begin{array}{l}\text { Descrever o caso clínico de uma criança que apresenta comportamento } \\
\text { agressivo e fala recorrente do tema da morte, e relatar a experiência da } \\
\text { equipe de autores na proposição de uma alternativa à medicalização por } \\
\text { meio da formação de uma Rede de Proteção e da aplicação Intersetorial do } \\
\text { conceito de Círculo de Segurança da Criança. }\end{array}$ & Relato de caso \\
\hline $\begin{array}{l}\text { Arpini et al. }{ }^{27} \\
(2015)\end{array}$ & $\begin{array}{l}\text { Apresentar as atividades desenvolvidas em um projeto de extensão que visa a } \\
\text { observar a relação entre crianças de } 0 \text { a } 2 \text { anos e suas mães nos atendimentos } \\
\text { realizados pelo Programa da Criança em uma UBS, com o intuito de detectar } \\
\text { possíveis riscos ao desenvolvimento infantil de modo precoce. }\end{array}$ & $\begin{array}{l}\text { Relato de } \\
\text { experiência }\end{array}$ \\
\hline $\begin{array}{l}\text { Gomes et al. }{ }^{23} \\
(2015)\end{array}$ & $\begin{array}{l}\text { Compreender sentidos e significados sobre SMI dos profissionais médicos } \\
\text { da Atenção Primária à Saúde (APS). }\end{array}$ & $\begin{array}{l}\text { Empírico/ } \\
\text { Qualitativo }\end{array}$ \\
\hline $\begin{array}{l}\text { Tszesnioski et } \\
\text { al. }^{26}(2015)\end{array}$ & $\begin{array}{l}\text { Descrever a rede de cuidados para crianças em sofrimento psíquico e } \\
\text { desenvolver intervenções no território, apontando mudanças ocorridas a } \\
\text { partir dessas ações. }\end{array}$ & $\begin{array}{l}\text { Empírico/ } \\
\text { Qualitativo/ } \\
\text { Pesquisa-ação }\end{array}$ \\
\hline $\begin{array}{l}\text { Silveira et al. }{ }^{28} \\
(2016)\end{array}$ & $\begin{array}{l}\text { Identificar as ações utilizadas pelos profissionais de saúde que trabalham } \\
\text { nas UBS da Família para reconhecer os casos de violência psicológica } \\
\text { contra a criança. }\end{array}$ & $\begin{array}{l}\text { Empírico/ } \\
\text { Qualitativo }\end{array}$ \\
\hline $\begin{array}{l}\text { Santos e } \\
\text { Celeri }^{15}(2017)\end{array}$ & $\begin{array}{l}\text { Estudar a aplicabilidade do Questionário de Capacidades e Dificuldades } \\
\text { (Strength and Difficulties Questionnaire, SDQ 2,4-p) como instrumento de } \\
\text { rastreamento, na AB, de problemas de SMI em pré-escolares; e caracterizar } \\
\text { os problemas de saúde mental da amostra, comparando dados do SDQ e } \\
\text { do Inventário de Comportamentos da Criança (Child Behavior Check List). }\end{array}$ & $\begin{array}{l}\text { Empírico/ } \\
\text { Quantitativo }\end{array}$ \\
\hline
\end{tabular}

Fonte: Elaborado pelos autores.

SMI realizadas no âmbito da $\mathrm{AB}$. As ações mais frequentes referiram-se à identificação/diagnóstico de problemas de SMI ${ }^{15,21,24-26}$ e ao encaminhamento para serviços de especialidades ${ }^{21,23-25}$. Alguns estudos fizeram referência ao trabalho de alguns profissionais em específico, enquanto outros descreveram intervenções realizadas por profissionais ou equipe de saúde em parceria com outras instituições ou através de algum programa de caráter local.

Os estudos que abordaram o trabalho do médico e do pediatra, em particular, indicaram 
como principais atividades aquelas relacionadas à identificação e ao encaminhamento, além de prescrição de medicação ${ }^{21,23,24}$. Tanaka e Lauridsen-Ribeiro ${ }^{21}$ descreveram que a conduta mais frequentemente adotada pelos pediatras frente a problemas de SMI de uma UBS de São Paulo foi a orientação $(23,6 \%)$ e o encaminhamento para serviço de saúde mental e Fonoaudiologia $(15,3 \%)$. Os autores ainda destacaram que $29,2 \%$ $(\mathrm{n}=21)$ das crianças com hipótese diagnóstica de problemas de saúde mental não apresentaram conduta médica registrada no prontuário.

Gomes et al. ${ }^{23}$, em investigação em UBSs e ESFs de Divinópolis, apresentaram a percepção de médicos e pediatras sobre suas intervenções. A atividade de orientação foi referida por esses profissionais. Sobre a administração da medicação, indicaram não haver diálogo com o especialista, de forma que ou a criança já chegava medicada, ou tinha a sua receita apenas renovada nas consultas. Os entrevistados não concordavam com a forma como os encaminhamentos estavam instituídos, com o desfecho quase sempre medicamentoso. No entanto, não propuseram intervenções diferentes dessas. Da mesma forma, relataram a não realização de atividades preventivas ou de acompanhamento de desenvolvimento, por considerarem uma responsabilidade dos profissionais da Enfermagem.

Já Becker et al. ${ }^{22}$ descreveram uma intervenção realizada por alunos de Medicina, a partir de uma experiência de estágio. $\mathrm{O}$ estudo de caso descreveu uma intervenção realizada em UBS para o acolhimento de uma criança ( 5 anos) encaminhada pela escola, que verbalizava desejo de morrer e agredir colegas. Devido a ineficácia da intervenção proposta e aos efeitos colaterais da medicação, o caso foi direcionado para a equipe de estagiários. Esta reorganizou o plano de cuidado a partir do conceito de Círculo de Segurança, que estabelece suporte emocional e instruções para pais e profissionais sobre a criação de um ambiente seguro para que a criança desenvolva suas emoções. Desta forma, articularam-se intervenções que contemplavam a família, a UBS e a escola frequentada pela criança, uma estratégia positiva e alternativa à patologização e à medicalização.

Particularmente sobre o trabalho do psicólogo, Braga e Morais $^{20}$ descreveram como a conduta mais frequentemente adotada por este profissional em UBS de São Paulo, em relação a uma amostra de 104 prontuários de crianças, a orientação familiar $(24,7 \%)$, seguida de terapia grupal $(20,5 \%)$ e terapia individual $(15,3 \%)$. En- tretanto, notaram diferenças entre os casos que não envolviam queixa escolar, pois nestes a intervenção mais adotada era a terapia individual. Em apenas $1 \%$ dos casos que procuraram a UBS com queixa escolar foi realizada entrevista com o professor. Para os autores, isto demonstra que os profissionais interpretam estas queixas como passíveis de tratamento clínico, desconsiderando uma complexa rede que envolve outras relações imbricadas nas dificuldades escolares.

Por outro lado, um trabalho interdisciplinar (Psicologia e Enfermagem) foi descrito por Arpini et al. ${ }^{27}$. Trata-se de um projeto de extensão realizado por alunos da UFSM junto ao Programa da Criança na cidade de Santa Maria-RS. As ações incluíram atendimentos, que abarcavam o trabalho da Enfermagem, através do acompanhamento e orientações gerais sobre o cuidado com o bebê, e da Psicologia, voltado aos aspectos relacionais (relações pais-bebê). Os recursos técnicos usados no trabalho da Psicologia foram observação orientada pelo IRDI (Indicadores Clínicos de Risco para o Desenvolvimento Infantil); entrevistas com familiares; orientações aos familiares e encaminhamento, quando necessário, para outros profissionais ou serviços de saúde. Segundo as autoras, tal projeto representa uma estratégia de detecção precoce de riscos ao desenvolvimento, e de prevenção e promoção em saúde.

Já Tszenioski et al. ${ }^{26}$ descreveram intervenções realizadas por estudantes de Terapia Ocupacional, a partir de um projeto de pesquisa-ação, articulado com uma unidade de $\mathrm{AB}$ de Recife. As intervenções foram apresentadas como possibilidades de atuação desses profissionais em SMI, cujo trabalho é caracterizado pela descoberta de habilidades que estimulem a potencialidade das crianças, a fim de promover maior independência e autonomia. As atividades de estimulação eram realizadas através de intervenções apoiadas na importância do brincar, incluindo treino de habilidades psicossociais e cognitivas. A equipe de pesquisa também avaliou a rede de atenção e traçou metas junto às famílias e equipes de saúde de diferentes serviços. Na avaliação dos autores, as intervenções propostas contribuíram para o fortalecimento da rede de cuidados, oportunizando maior articulação entre a equipe de $\mathrm{AB}$ e o serviço especializado, além do fortalecimento de vínculos entre algumas das crianças atendidas e suas famílias e escolas.

As ações apresentadas até então fazem referência a intervenções desenvolvidas por alguns profissionais em UBS e ESF ou em projetos em parceria com universidades. Todavia, Carvalho et $a .^{5}$ descreveram, a partir de diferentes atores 
do serviço, atividades de um programa governamental específico, de caráter local, denominado Programa Municipal de Intervenção Precoce (PMIP). Trata-se de uma iniciativa promovida pela Prefeitura de Campina Grande-PB, que busca dar suporte às crianças entre 0 e 6 anos que têm/estão em risco para algum transtorno em seu desenvolvimento e suas famílias, tendo como objetivo identificar problemas no desenvolvi- mento ou prevenir agravos, além da promoção da integração e da inclusão dessas crianças na família e na sociedade. Segundo os autores, dentro do contexto da $\mathrm{AB}$, ainda que os profissionais de distintas atuações e formações reconheçam em seu trabalho um momento oportuno para a intervenção precoce e a detecção de sinais de risco, muitos deles não se sentem capacitados para tais intervenções.

Quadro 3. Características metodológicas dos artigos analisados $(\mathrm{n}=13)$.

\begin{tabular}{|c|c|c|c|}
\hline $\begin{array}{l}\text { Autores/ } \\
\text { Ano }\end{array}$ & $\begin{array}{l}\text { Composição da amostra/ } \\
\text { participantes }\end{array}$ & $\begin{array}{l}\text { Forma de coleta (alvo da aplicação) e análise dos } \\
\text { dados }\end{array}$ & $\begin{array}{c}\text { Nível de } \\
\text { evidência } \\
\text { (conforme } \\
\text { critérios de } \\
\text { Souza et al. } .^{19} \text { ) }\end{array}$ \\
\hline $\begin{array}{l}\text { Tanaka e } \\
\text { Lauridsen- } \\
\text { Ribeiro }^{24} \\
(2006)\end{array}$ & $\begin{array}{l}\text { (Adequadamente descrita) } \\
411 \text { crianças ( } 5 \text { - } 11 \text { anos), } \\
206 \text { pais e } 11 \text { pediatras de } \\
\text { uma UBS do município de } \\
\text { São Paulo (SP) }\end{array}$ & $\begin{array}{l}\text { Coleta } \\
\text { (Adequadamente descrita) } \\
\text { - Prontuário médico (crianças) } \\
\text { - Questionário de Capacidades e Dificuldades } \\
\text { (SDQ) e Inventário de Comportamento da } \\
\text { Infância e Adolescência (CBCL) (responsáveis } \\
\text { pelas crianças) } \\
\text { - Questionários para identificação de preocupação } \\
\text { relativa a problemas de saúde mental (pais e mães) } \\
\text { - Entrevistas semiestruturadas (pediatras) } \\
\text { Análise } \\
\text { (Adequadamente descrita) } \\
\text { - Análises estatísticas } \\
\text { - Análises temáticas das entrevistas }\end{array}$ & Nível 4 \\
\hline $\begin{array}{l}\text { Braga e } \\
\text { Morais }^{20} \\
(2007)\end{array}$ & $\begin{array}{l}\text { (Adequadamente descrita) } \\
104 \text { crianças (6-12 anos) que } \\
\text { demandaram, no segundo } \\
\text { trimestre de } 2005 \text {, a área } \\
\text { de saúde mental de UBS da } \\
\text { região norte do município } \\
\text { de São Paulo (SP) }\end{array}$ & $\begin{array}{l}\text { Coleta } \\
\text { (Pouco detalhada) } \\
\text { - Prontuário ( } \mathrm{n}=104 \text { crianças) } \\
\text { Análise } \\
\text { (Pouco detalhada) } \\
\text { - Análises estatísticas }\end{array}$ & Nível 4 \\
\hline $\begin{array}{l}\text { Ferriolli et } \\
\text { al. }^{2}(2007)\end{array}$ & $\begin{array}{l}\text { (Adequadamente descrita) } \\
100 \text { crianças (6-12 } \\
\text { anos), e seus familiares, } \\
\text { principalmente mães } \\
\text { biológicas ( } 82 \%), \\
\text { cadastradas em PSF no } \\
\text { município de Ribeirão Preto } \\
\text { (SP) }\end{array}$ & $\begin{array}{l}\text { Coleta } \\
\text { (Adequadamente descrita) } \\
\text { - Questionário de Capacidades e Dificuldades } \\
\text { (SDQ) para rastreio de PSM nas crianças } \\
\text { (cuidadores) } \\
\text { - Inventário de Recursos do Ambiente Familiar } \\
\text { (RAF) (cuidadores) } \\
\text { - Escala de Nível Socioeconômicocultural } \\
\text { (cuidadores) } \\
\text { - Escala de Eventos Adversos (EEA) (cuidadores) } \\
\text { - Inventário de Sintomas de Estresse para Adultos } \\
\text { (ISSL) (cuidadores) } \\
\text { - Inventário de Depressão de Beck (BDI) } \\
\text { (cuidadores) } \\
\text { Análise } \\
\text { (Adequadamente descrita) } \\
\text { - Análises estatísticas }\end{array}$ & Nível 4 \\
\hline
\end{tabular}


Quadro 3. Características metodológicas dos artigos analisados $(n=13)$.

\begin{tabular}{|c|c|c|c|}
\hline $\begin{array}{l}\text { Autores/ } \\
\text { Ano }\end{array}$ & $\begin{array}{l}\text { Composição da amostra/ } \\
\text { participantes }\end{array}$ & $\begin{array}{l}\text { Forma de coleta (alvo da aplicação) e análise dos } \\
\text { dados }\end{array}$ & $\begin{array}{l}\text { Nível de } \\
\text { evidência } \\
\text { (conforme } \\
\text { critérios de } \\
\text { Souza et al. } .^{19} \text { ) }\end{array}$ \\
\hline $\begin{array}{l}\text { Tanaka e } \\
\text { Lauridsen- } \\
\text { Ribeiro }^{21} \\
(2009)\end{array}$ & $\begin{array}{l}\text { (Adequadamente descrita) } \\
411 \text { crianças (5-11 anos), } \\
206 \text { pais e } 11 \text { pediatras de } \\
\text { uma UBS do município de } \\
\text { São Paulo (SP) }\end{array}$ & $\begin{array}{l}\text { Coleta } \\
\text { (Pouco detalhada) } \\
\text { - Prontuário médico das crianças } \\
\text { - Questionário de Capacidades e Dificuldades } \\
\text { (SDQ) e Inventário de Comportamento da } \\
\text { Infância e Adolescência (CBCL) (responsáveis } \\
\text { pelas crianças) } \\
\text { - Questionário para caracterização da família } \\
\text { (responsáveis) } \\
\text { - Entrevistas semiestruturadas (pediatras) } \\
\text { Análise } \\
\text { (Pouco detalhada) } \\
\text { - Análises estatísticas } \\
\text { - Análises temáticas das entrevistas }\end{array}$ & Nível 4 \\
\hline $\begin{array}{l}\text { Cavalcante } \\
\text { et al. }{ }^{25} \\
(2012)\end{array}$ & $\begin{array}{l}\text { (Adequadamente descrita) } \\
6 \text { trabalhadores da ESF } \\
\text { e CAPS envolvidos nas } \\
\text { atividades de apoio matricial } \\
\text { em saúde mental e familiares } \\
\text { de crianças atendidas } \\
\text { durante essas atividades, do } \\
\text { município de Fortaleza (CE), } \\
\text { nas Secretarias Executivas } \\
\text { Regionais (SER) IV e V. }\end{array}$ & $\begin{array}{l}\text { Coleta } \\
\text { (Adequadamente descrita) } \\
\text { - Entrevistas semiestruturadas (profissionais } \\
\text { envolvidos no apoio matricial e familiares de } \\
\text { crianças atendidas) } \\
\text { Análise } \\
\text { (Adequadamente descrita) } \\
\text { - Análise hermenêutica fenomenológica de Paul } \\
\text { Ricoeur (entrevistas) }\end{array}$ & Nível 4 \\
\hline $\begin{array}{l}\text { Carvalho } \\
\text { et al. } .^{5} \\
(2013)\end{array}$ & $\begin{array}{l}\text { (Adequadamente descrita) } \\
10 \text { profissionais que atuam } \\
\text { em três Equipes da ESF ( } 3 \\
\text { enfermeiros, } 3 \text { auxiliares, } 1 \\
\text { assistente social, } 2 \text { médicos } \\
\text { e } 1 \text { fisioterapeuta). Todos } \\
\text { atuavam nos serviços há } \\
\text { mais de seis meses e estavam } \\
\text { envolvidos com o programa } \\
\text { de IP implementado na cidade } \\
\text { de Campina Grande (PB) }\end{array}$ & $\begin{array}{l}\text { Coleta } \\
\text { (Pouco detalhada) } \\
\text { - Entrevistas semiestruturadas (profissionais) } \\
\text { Análise } \\
\text { (Adequadamente descrita) } \\
\text { - Análise de conteúdo, tipo categorial temática }\end{array}$ & Nível 4 \\
\hline $\begin{array}{l}\text { Sinibaldi }{ }^{6} \\
(2013)\end{array}$ & $\begin{array}{l}\text { (Não há método } \\
\text { estruturado) } \\
\text { Estudo teórico }\end{array}$ & $\begin{array}{l}\text { (Não há método estruturado) } \\
\text { Análise e discussão da literatura sobre a relação } \\
\text { entre os serviços de atenção primária e os cuidados } \\
\text { dispensados à infância no Brasil. }\end{array}$ & Não se aplica \\
\hline $\begin{array}{l}\text { Becker et } \\
\text { al. }^{22}(2014)\end{array}$ & $\begin{array}{l}\text { (Adequadamente descrita) } \\
\text { Menino de } 5 \text { anos, com } \\
\text { diversas reclamações da } \\
\text { creche, que frequenta em } \\
\text { período integral, acerca de } \\
\text { seu comportamento agressivo } \\
\text { e violento. Foi diagnosticado } \\
\text { e medicado pelo Centro } \\
\text { de Saúde. Apesar de ações } \\
\text { (conversas, trabalho em } \\
\text { grupos, acompanhamento } \\
\text { psicológico e psiquiátrico), } \\
\text { a criança manteve esse } \\
\text { comportamento. }\end{array}$ & $\begin{array}{l}\text { (Adequadamente descrita) } \\
\text { Relato de caso: Descrição de intervenções } \\
\text { realizadas no caso por um grupo de alunos da } \\
\text { UNICAMP, a partir do conceito de Círculo de } \\
\text { Segurança. }\end{array}$ & Nível 5 \\
\hline
\end{tabular}


Quadro 3. Características metodológicas dos artigos analisados $(\mathrm{n}=13)$.

\begin{tabular}{|c|c|c|c|}
\hline $\begin{array}{l}\text { Autores/ } \\
\text { Ano }\end{array}$ & $\begin{array}{l}\text { Composição da amostra/ } \\
\text { participantes }\end{array}$ & $\begin{array}{l}\text { Forma de coleta (alvo da aplicação) e análise dos } \\
\text { dados }\end{array}$ & $\begin{array}{l}\text { Nível de } \\
\text { evidência } \\
\text { (conforme } \\
\text { critérios de } \\
\text { Souza et al. } .^{19} \text { ) }\end{array}$ \\
\hline $\begin{array}{l}\text { Arpini et } \\
\text { al. }^{27}(2015)\end{array}$ & $\begin{array}{l}\text { (Adequadamente descrita) } \\
\text { Relato de experiência sobre as } \\
\text { atividades de um projeto de } \\
\text { extensão, realizado por alunos } \\
\text { de psicologia da UFSM, que } \\
\text { intervém sobre a relação } \\
\text { mãe-filho, qualificando-a e } \\
\text { detectando possíveis sinais de } \\
\text { risco para o desenvolvimento } \\
\text { infantil. }\end{array}$ & $\begin{array}{l}\text { (Adequadamente descrita) } \\
\text { Relato de experiência: Apresentação das atividades } \\
\text { realizadas pelo curso de extensão a partir de } \\
\text { sua caracterização, método de ação e principais } \\
\text { resultados. }\end{array}$ & Nível 5 \\
\hline $\begin{array}{l}\text { Gomes et } \\
\text { al. }^{23}(2015)\end{array}$ & $\begin{array}{l}\text { (Adequadamente descrita) } \\
12 \text { médicos de equipes de } \\
\text { ESF e } 5 \text { pediatras atuantes } \\
\text { em UBS sem ESF, com tempo } \\
\text { de formação entre dois e } \\
35 \text { anos }(\mathrm{M}=20,9) \text {, e tempo } \\
\text { de atuação na US entre seis } \\
\text { meses a } 16 \text { anos }(\mathrm{M}=6,4), \text { na } \\
\text { cidade de Divinópolis }(\mathrm{MG}) \text {. }\end{array}$ & $\begin{array}{l}\text { Coleta } \\
\text { (Pouco detalhada) } \\
\text { - Entrevistas semiestruturadas (profissionais) } \\
\text { Análise } \\
\text { (Adequadamente descrita) } \\
\text { - Análise pela perspectiva sócio-histórica ou } \\
\text { histórico-cultural. }\end{array}$ & Nível 4 \\
\hline $\begin{array}{l}\text { Tszesnioski } \\
\text { et al. }{ }^{26} \\
(2015)\end{array}$ & $\begin{array}{l}\text { (Adequadamente descrita) } \\
7 \text { crianças (de } 1 \text { a } 5 \text { ou de } 6 \\
\text { a } 9 \text { anos), com história de } \\
\text { sofrimento psíquico, e seus } \\
\text { familiares, cadastrados numa } \\
\text { (USF) do Distrito Sanitário } \\
\text { IV da cidade do Recife (PE). }\end{array}$ & $\begin{array}{l}\text { Coleta } \\
\text { (Adequadamente descrita) } \\
\text { - Questionário semiestruturado para caracterização } \\
\text { dos participantes, dados clínicos, rede de cuidado } \\
\text { (familiar/responsável) } \\
\text { - Diário de campo } \\
\text { - Fotografias das visitas domiciliares } \\
\text { Análise } \\
\text { (Adequadamente descrita) } \\
\text { Pesquisa-ação: Informações do questionário e visitas } \\
\text { domiciliares subsidiaram as intervenções analisadas } \\
\text { - Análise temática (registros das intervenções - } \\
\text { diários de campo e fotografias) } \\
\text { - Construção de ecomapa para a apresentação dos } \\
\text { resultados }\end{array}$ & Nível 5 \\
\hline $\begin{array}{l}\text { Silveira et } \\
\text { al. }^{28}(2016)\end{array}$ & $\begin{array}{l}\text { (Adequadamente descrita) } \\
7 \text { profissionais de uma UBS de } \\
\text { uma cidade do sul do Brasil (1 } \\
\text { Agente Comunitário de Saúde, } \\
2 \text { Enfermeiros, } 2 \text { Médicos e } 2 \\
\text { Técnicos de Enfermagem. } \\
\end{array}$ & $\begin{array}{l}\text { Coleta } \\
\text { (Adequadamente descrita) } \\
\text { - Entrevistas semiestruturadas (profissionais) } \\
\text { Análise } \\
\text { (Adequadamente descrita) } \\
\text { - Análise de temática de conteúdo (entrevistas) }\end{array}$ & Nível 4 \\
\hline $\begin{array}{l}\text { Santos e } \\
\text { Celeri }^{15} \\
(2017)\end{array}$ & $\begin{array}{l}\text { (Adequadamente descrita) } \\
48 \text { crianças ( } 31 \text { a } 50 \text { meses) } \\
\text { cadastradas em UBS de } \\
\text { uma cidade do interior da } \\
\text { região metropolitana de } \\
\text { São Paulo, sobre as quais } \\
\text { os responsáveis forneceram } \\
\text { informações. }\end{array}$ & $\begin{array}{l}\text { Coleta } \\
\text { (Adequadamente descrita) } \\
\text { - Critério de Classificação Econômica Brasil } \\
\text { (CCEB) (responsáveis) } \\
\text { - Questionário de Capacidades e Dificuldades } \\
\text { (SDQ) (responsáveis) } \\
\text { - Inventário de Comportamentos para Crianças } \\
\text { entre } 1 \frac{1}{2} \text { e } 5 \text { anos (CBCL 1 1⁄2-5) (responsáveis) } \\
\text { Análise } \\
\text { (Adequadamente descrita) } \\
\text { - Análises estatísticas }\end{array}$ & Nível 4 \\
\hline
\end{tabular}

Fonte: Elaborado pelos autores. 
Outros artigos ${ }^{21,28}$ ainda fizeram menção específica aos casos de violência psicológica acolhidos na $\mathrm{AB}$, devido à sua repercussão na SMI, e à necessária intervenção para interromper o ciclo de maus tratos. Especificamente, Silveira et al. ${ }^{28}$ apontaram que os diferentes profissionais da $\mathrm{AB}$ de uma cidade do sul do Brasil priorizavam os sinais físicos de violência e subestimavam os sinais psicológicos. Os autores ainda identificaram a ausência de uma ação específica para detectar violência psicológica contra crianças e dificuldades dos profissionais para intervir de maneira eficaz.

Como visto até então, diversos estudos identificaram o encaminhamento como parte importante das ações em SMI a serem realizadas por profissionais da $\mathrm{AB}$. No entanto, Cavalcante et al. ${ }^{25}$ ressaltam que, ao acolher e fazer avaliação clínica para posterior encaminhamento, o profissional da $\mathrm{AB}$ deve saber reconhecer qual a demanda que o serviço é capaz de atender e qual, de fato, deve ser encaminhada para atendimento especializado. Por fim, ainda que não se trate de uma ação em SMI diretamente voltada à população assistida, Cavalcante et al. ${ }^{25}$ fizeram menção ao apoio matricial como ferramenta importante na retaguarda das atividades do profissional da AB. Trata-se de uma estratégia que, muitas vezes, viabiliza que intervenções em SMI sejam realizadas no contexto da $\mathrm{AB}$.

Salienta-se, ainda, que diversas ações descritas nos estudos revisados foram desenvolvidas a partir de uma articulação com diferentes setores. Dentre elas, destacam-se a interlocução com as famílias ${ }^{5,20-23,27,26}$, rede de assistência à saúde e infância ${ }^{21,23,25-28}$; e instituições escolares ${ }^{20,22,26}$.

\section{Dificuldades e proposições para a implementação das ações em SMI na AB}

Por fim, diversos artigos ( $\mathrm{n}=12$ artigos) também discutiram as dificuldades enfrentadas para a implementação efetiva das ações apresentadas, assim como apresentaram proposições para saná-las. Algumas dificuldades referidas relacionavam-se aos profissionais, tais como despreparo ou insegurança para lidar com a população infantil que necessita de atenção em saúde men$\operatorname{tal}^{2,5,15,20,21,23-25,28}$. Esta limitação foi referida algumas vezes a partir de uma dificuldade pessoal, relacionada a aspectos emocionais do profissional, ou a partir de uma dificuldade no reconhecimento das demandas passíveis de serem atendidas na $\mathrm{AB}$ ou que devam ser encaminhadas para as especialidades ${ }^{24-26}$. Mencionam, ainda, a maior atenção às queixas orgânicas em detrimento dos aspectos psicológicos ${ }^{21,23,24,28}$, sendo estes, por vezes, minimizados, tanto em relação a condições clínicas ${ }^{15}$ quanto em relação a casos de violência psicológica ${ }^{28}$.

Especificamente sobre o pediatra, foram referidas dificuldades no reconhecimento de problemas de SMI, de modo que esses profissionais percebem não ter o mesmo domínio para lidar com questões relacionadas à saúde mental em comparação a outra especialidade ${ }^{21,24}$. Algumas justificativas apontadas para a incapacidade de acolher a demanda de SMI relacionaram-se à linguagem do campo da saúde mental, a características dos próprios profissionais e a falhas na formaçãa ${ }^{21,24}$. Nesta direção, alguns estudos ${ }^{2,15,28}$ abordaram a importância da detecção precoce de problemas de SMI e propuseram a implementação de protocolos sensíveis à infância para qualificar esse processo.

No que tange aos profissionais da Psicologia, foi salientado que estes muitas vezes têm dificuldades em buscar outras formas de intervir para além da psicoterapia individual, devido à formação predominantemente clínica ${ }^{20}$. Nesse sentido, reconhece-se que a formação e a capacitação dos profissionais ainda se constituem na contramão das diretrizes da reforma psiquiátrica e de saúde mental, privilegiando as intervenções e a psicopatologia tradicional e fragilizando, por outro lado, o atendimento integral ${ }^{25,28}$. De fato, a compreensão fragmentada de saúde e dos processos subjacentes à patologização foi descrita em alguns artigos como um entrave ao cuidado em SMI na $\mathrm{AB}^{5,6,20,22,23,25}$.

Como visto, diversos estudos apontaram a necessidade de maiores investimentos na formação dos profissionais, para a consolidação de práticas de $\mathrm{SMI}$ na $\mathrm{AB}^{2,5,6,6,20,21,24-26,28}$. Nesse sentido, alguns autores ${ }^{20,21,28}$ ressaltaram a necessidade de investimentos tanto na formação continuada quanto na revisão dos currículos de graduação. Entre as sugestões, identificou-se propostas de formação que incluam práticas de intervenção $0^{21} \mathrm{e}$ que possam quebrar a lógica dos especialismos e do privilégio dos aspectos biológicos em relação aos de saúde mental ${ }^{6,28}$.

Para além de aspectos individuais e formativos, outras dificuldades para a implementação de ações de SMI na AB dizem respeito à organização e à articulação dos serviç̧os ${ }^{5,21,25,26,28}$. Nessa direção, foram elencadas dificuldades relacionadas ao encaminhamento, tais como demanda excessiva, desconhecimento dos profissionais em relação ao funcionamento da rede, bem como 


\section{Discussão e considerações finais}

Esta revisão buscou caracterizar as ações em SMI no contexto da $\mathrm{AB}$, por meio de uma revisão integrativa da literatura brasileira (2006 a 2017). A partir da análise de 13 artigos, identificou-se um aumento na publicação sobre esta temática nos últimos anos, provavelmente em decorrência do tempo de implementação da $\mathrm{PNAB}$, ocorrida em 2006. Os artigos revisados indicaram também o reconhecimento da $\mathrm{AB}$ como um importante campo de ação em SMI. As principais ações descritas nesse âmbito se caracterizaram pela identificação de problemas de SMI e encaminhamento para atendimento por especialidades.

Alguns estudos descreveram ações específicas de algumas categorias profissionais, como médicos, pediatras e psicólogos. No entanto, de modo geral, $o$ atendimento de problemas menos severos de saúde mental da infância, que, em princípio, poderiam ser acompanhados no âmbito da $\mathrm{AB}^{21,25}$, foi pouco mencionado. Este processo pode ser o reflexo das dificuldades das equipes de $\mathrm{AB}$ em receber o suporte necessário para o atendimento à população infanto-juvenil, uma vez que a literatura tem indicado obstáculos na articulação com as equipes especializadas via matriciamento ${ }^{25,29,30}$. Por outro lado, também pode estar relacionado a aspectos da formação destes profissionais, ainda pautada pela lógica dos especialismos, de maneira que não percebem as questões ligadas à saúde mental como parte de seu trabalho na $\mathrm{AB}^{6}$. Neste sentido, cabe o questionamento se, de fato, estes atendimentos não ocorrem, e são encaminhados diretamente às especialidades, ou se não são reconhecidos pelos profissionais enquanto intervenções em saúde mental.

Nesta revisão também foram identificadas intervenções particulares, de caráter local ou em parcerias com universidades, através de estágios, projeto de extensão e pesquisa-intervenção. Nestas, identifica-se uma compreensão mais integral da infância, contemplando atuações de caráter interdisciplinar ou intersetorial e atenção às relações entre os agentes e instituições envolvidos na intervenção. Estas experiências demonstram que a interlocução entre as instituições de ensino superior e a $A B$ tem muito a contribuir para a implementação de ações efetivas de SMI, entendendo que esta é uma troca que possibilita identificar, além de um processo formativo acadêmico atento às especificidades da saúde pública, a possibilidade dos serviços repensarem e ampliarem suas ações e intervenções em saúde mental. Junto a isto, as intervenções de caráter local também apontaram caminhos possíveis para uma atenção cuidadosa às demandas específicas e à organização do trabalho de cada localidade $e^{5,22,26,27}$.

Alguns estudos revisados descreveram intervenções que envolvem diferentes setores em articulação com as ações desenvolvidas pela $\mathrm{AB}$. Destacam-se, neste sentido, as articulações com as famílias $5,20-23,26,27$, apontadas como importantes tanto para o adoecimento como para a promoção de saúde mental; com os demais serviços da rede de assistência à saúde e infância ${ }^{21,23,25-28}$, tanto em relação aos serviços para onde são realizados os encaminhamentos, e sua necessária interlocução na composição dos projetos terapêuticos, quanto àqueles que oferecem o suporte necessário para que a própria $\mathrm{AB}$ possa atender os casos menos complexos; e também articulações com as instituições escolares ${ }^{20,22,26}$, por serem responsáveis por grande parte dos encaminhamentos e reconhecidas com potencial capacidade de produzir ou minimizar o sofrimento psíquico infantil.

Desse modo, reitera-se a importância das intervenções intersetoriais como estratégia de composição de uma rede de atenção efetiva. Além disso, destaca-se a importância de ações e intervenções em SMI na $A B$ se pautarem pela territorialidade, de forma a organizar as estratégias de atenção entre os serviços de saúde e demais redes de cuidado e apoio, tal como a família e a escola, levando em consideração o contexto e realidade do território; e pela integralidade do cuidado, na articulação de diferentes saberes e serviços da rede, contemplando, para além da saúde mental, o vínculo e a inserção social como importantes fatores de promoção de saúde ${ }^{5,22,26,27}$. Cabe, ainda, ressaltar a amplitude dos efeitos das intervenções na $A B$, que, para além da promoção e prevenção em saúde, podem diminuir a sobrecarga sobre os serviços de especialidades, qualificando a atenção em todos os níveis.

Os resultados desta revisão permitem perceber também que algumas dificuldades identificadas nos artigos quanto às ações em SMI na $\mathrm{AB}$ no Brasil se mantiveram ao longo do período analisado. As dificuldades para implementar as 
ações evidenciam incoerências entre as diretrizes e como, de fato, estão organizadas as intervenções da rede. A identificação destas contradições converge com a literatura ${ }^{31,32}$, que mostra que os profissionais da $A B$, por vezes, orientam suas ações a partir de um modelo tradicional e hierarquizado de assistência. Particularmente nesta revisão, destacou-se a necessidade de investimento na ampliação da formação dos profissionais, contribuindo tanto para a sua qualificação técnica quanto em relação a como compreendem o cuidado em SMI.

Outros estudos de revisão bibliográfica que articularam saúde mental e $A B$ também apontaram algumas características dessa articulação identificadas neste trabalho, como as dificuldades dos profissionais, obstáculos no funcionamento dos serviços e ausência de formação na área $^{33-35}$. Nesse sentido, é possível perceber que a implementação de estratégias de intervenção em saúde mental ainda é um desafio para a $\mathrm{AB}$ e para toda a rede. Especificamente sobre a infância, a complexidade pode se tornar ainda maior, devido às especificidades desta população. Estes entraves indicam questões complexas, que ultrapassam o contexto da $A B$, mas dizem respeito à estruturação dos serviços e sua articulação como um todo. Neste sentido, fica claro que as mudanças efetivas para modificar este panorama necessitam envolver ações em diferentes níveis e constante reflexão, a partir da formação continuada, da educação permanente, da revisão dos currículos dos cursos da área da saúde, além do necessário acompanhamento de gestão e reestruturação dos serviços, tendo em vista sobre como, de fato, eles vêm operando.

Em relação aos aspectos metodológicos, salientam-se algumas considerações. Diversos estudos caracterizaram a amostra de crianças-alvo de cuidados em saúde mental tanto a partir de instrumentos padronizados ${ }^{2,15,21,24}$ quanto a partir de registros de prontuários, questionários ou das percepções dos próprios profissionais ${ }^{20,23,26}$. Ambas as estratégias permitem a identificação da demanda em SMI na AB, o que é particularmente importante, tendo em vista que identificar a real necessidade de atenção permite ações mais assertivas, tanto a nível de intervenção, por parte dos profissionais, quanto a nível de gestão, através da implementação ou atualização de serviços atentos às especificidades da população. Por outro lado, particularmente sobre a percepção dos profissionais, torna-se interessante compreender como, de fato, as estratégias de cuidado estão sendo operacionalizadas, pois estes dados podem servir de subsídio para a implementação de atividades de educação continuada que considerem o atual panorama dos serviços e profissionais da $\mathrm{AB}$, qualificando $\mathrm{o}$ atendimento à população.

A partir do exposto, espera-se que esta revisão contribua para ampliar o conhecimento sobre o atual estado da arte das publicações científicas brasileiras que abordam ações e intervenções sobre a SMI no contexto da $\mathrm{AB}$ e promova reflexões sobre a atuação dos profissionais. Este trabalho possui algumas limitações, sobretudo relacionadas à restrição do material analisado, tendo em vista que não foram incluídos outros tipos de publicação científica que não artigos. Além disso, o número escasso de publicações brasileiras sobre o tema denota a necessidade de maior divulgação das ações de SMI realizadas no âmbito da AB. Ainda, a identificação de apenas estudos com níveis de evidência 4 e 5 sugere a necessidade da realização de pesquisas a partir outros de outros delineamentos, especialmente quantitativos e experimentais, para, por exemplo, qualificar a avaliação dessas intervenções ${ }^{19}$.

Da mesma forma, recomenda-se a ampliação dos estudos de caracterização dessa demanda na $\mathrm{AB}$, para um melhor planejamento das ações e intervenções dos profissionais. As dificuldades encontradas nas buscas dos artigos sugerem também a necessidade de padronização na indexação de termos descritores sobre esta temática, tendo em vista que se trata de um campo de estudo e atuação singular, necessário e de suma importância para a área da saúde. 


\section{Colaboradores}

GC Esswein trabalhou em todas as etapas deste trabalho. AF Rovaris e GP Rocha trabalharam na concepção, metodologia e revisão. DC Levandowski trabalhou na concepção, estruturação, análise crítica e revisão de todo o texto.

\section{Agradecimentos}

Ao Conselho Nacional de Desenvolvimento Científico e Tecnológico (CNPq) pelo apoio financeiro na modalidade de Bolsa Produtividade em Pesquisa da autora DC Levandowski, e de Bolsa de Doutorado-GD (vinculada ao PPG Psicologia da UFRGS) do autor GC Esswein.

\section{Referências}

1. Arpini DM, Santos BR. Programa da Criança: espaço de promoção de saúde e fortalecimento dos vínculos. Rev Psicol Arg 2007; 25(49):155-164.

2. Ferriolli SHT, Marturano EM, Puntel LP. Contexto familiar e problemas de saúde mental infantil no Programa Saúde da Família. Rev Saude Publica 2007; 41(2):251-259.

3. Goodman A, Joyce R, Smith JP. The long shadow cast by childhood physical and mental problems on adult life. Proc Natl Acad Sci USA 2011; 108(15):6032-6037.

4. Ramires VRR, Benetti SPC, Silva FJL, Flores GG. Saúde mental de crianças no Brasil: Uma revisão de literatura. Inter Psicol 2009; 13(2):311-322.

5. Carvalho RN, Gondim ACS, Azevedo EB, Cavalcanti PB, Ferreira Filha MO, Queiroz D. Concepções dos profissionais da Estratégia Saúde da Família sobre intervenção precoce em saúde mental. Rev Gaucha Enferm 2013; 34(1):79-85.

6. Sinibaldi B. Saúde mental infantil e atenção primária: relações possíveis. Rev Psicol UNESP 2013; 12(2):6172.

7. Brasil. Ministério da Saúde (MS). Política Nacional de Atenção Básica. Séria Pactos pela Saúde. Brasília: MS; 2006.

8. Brasil. Ministério da Saúde (MS). Política Nacional de Atenção Básica. Brasília: MS; 2012.

9. Brasil. Ministério da Saúde (MS). Portaria no 2.436, de 21 de setembro de 2017. Aprova a Política Nacional de Atenção Básica, estabelecendo a revisão de diretrizes para a organização da Atenção Básica, no âmbito do Sistema único de Saúde (SUS). Diário Oficial da União 2017; 21 set.

10. Brasil. Ministério da Saúde (MS). Portaria no 154 , de 24 de janeiro de 2008. Cria os Núcleos de Apoio à Saúde da Família - NASF. Diário Oficial da União 2008; 25 jan.

11. Kantorski LP, Coimbra VCC, Oliveira NA, Nunes CK, Pavani FM, Sperb LCSO. Atenção psicossocial infantojuvenil: interfaces com a rede de saúde pelo sistema de referência e contrarreferência. Texto Contexto Enferm 2017; 26(3):1-10.

12. Jimenez L. Psicologia na Atenção Básica à Saúde: demanda, território e integralidade. Psicol Soc 2011; 23:129-139.

13. Borges CF, Baptista TWDF. O modelo assistencial em saúde mental no Brasil: a trajetória da construção política de 1990 a 2004. Cad Saude Publica 2008; 24(2):456-468.

14. Brasil. Ministério da Saúde (MS). Portaria no 3.088, de 23 de dezembro de 2011. Institui a Rede de Atenção Psicossocial para pessoas com sofrimento ou transtorno mental e com necessidades decorrentes do uso de crack, álcool e outras drogas, no âmbito do Sistema Único de Saúde (SUS). Diário Oficial da União; 2011.

15. Santos, RGH, Celeri EHRV. Rastreamento de problemas de saúde mental em crianças pré-escolares no contexto da atenção básica à saúde. Rev Paul Pediatr 2017; 36(1):82-90.

16. Paula CS, Coutinho ES, Mari JJ, Rohde LA, Miguel EC, Bordin IA. Prevalence of psychiatric disorders among children and adolescents from four Brazilian regions. Rev Bras Psiquiatr 2015; 37(2):178-179. 
17. Mendes KDS, Silveira RCCP, Galvão CM. Revisão integrativa: método de pesquisa para a incorporação de evidências na saúde e na enfermagem. Texto Contexto Enferm 2008; 17(4):758-764.

18. Botelho LLR, Cunha CCA, Macedo M. O método de revisão integrativa nos estudos organizacionais. Gest Soc 201; 5(11):123-136.

19. Souza MT, Silva MD, Carvalho R. Revisão integrativa: o que é e como fazer. Einstein 2010; 8(1):102-106.

20. Braga SG, Morais MLS. Queixa escolar: atuação do psicólogo e interfaces com a educação. Psicol USP 2007; 18(4):35-51.

21. Tanaka OY, Lauridsen-Ribeiro E. Ações de saúde mental na atenção básica: caminho para ampliação da integralidade da atenção. Cien Saude Colet 2009; 14(2):477-486.

22. Becker ALMM, Souza PH, Oliveira MM, Paraguay NLBB. A articulação da rede de proteção à criança e a aplicação intersetorial do círculo de segurança como alternativas à medicalização. Rev Paul Pediatr 2014; 32(3):247-251.

23. Gomes FMA, Cintra AMO, Ricas J, Vecchia MD. Saúde mental infantil na atenção primária à saúde: discursos de profissionais médicos. Saude Soc 2015; 24(1):244-258.

24. Tanaka OY, Lauridsen-Ribeiro E. Desafio para a atenção básica: incorporação da assistência em saúde. Cad Saude Publica 2006; 22(9):1845-1853.

25. Cavalcante CM, Jorge MSB, Santos DCM. Onde está a criança? desafios e obstáculos ao apoio matricial de crianças com problemas de saúde mental. Physis 2012; 22(1):161-178.

26. Tszesnioski LC, Nóbrega KBG, Lima MLLT, Fagundes VLD. Construindo a rede de cuidados em saúde mental infantojuvenil: intervenções no território. Cien Saude Colet 2015; 20(2):363-370.

27. Arpini DM, Zanatta E, Marchesan RQ, Savegnago SDO, Bernardi PH. Intervenções precoces na infância: observando a relação mãe-bebê em um serviço de saúde. Psicol Rev 2015; 21(1):37-50.

28. Silveira TBD, Oliveira AMND, Algeri S, Susin LRO, Baisch ALM, Marques L A, Silva PAD. A invisibilidade da violência psicológica pelos profissionais de saúde. Rev Bras Crescimento Desenvolv Hum 2016; 26(3):345351.

29. Machado DKSM, Camatta MW. Apoio matricial como ferramenta de articulação entre a saúde mental e a atenção primária à saúde. Cad Saude Colet 2013; 21(2):224-232.
30. Gama CAP, Campos RO. Saúde Mental na Atenção Básica - Uma pesquisa bibliográfica exploratória em periódicos de saúde coletiva (1997-2007). Cad Bras Saude Mental 2009; 1(2):1984-2147.

31. Paula CS, Zaqueu L, Thais V, Lowenthal R., Miranda C. Atuação de psicólogos e estruturação de serviços públicos na assistência à saúde mental de crianças e adolescentes. Psicol Teor Prat 2011; 13(3):81-95.

32. Teixeira MB, Couto MCV, Delgado PGG. Atenção básica e cuidado colaborativo na atenção psicossocial de crianças e adolescentes: facilitadores e barreiras. Cien Saude Colet 2017; 22(6):1933-1942.

33. Martins AKL, Braga VAB, Souza AMA. Práticas em saúde mental na estratégia saúde da família: Um estudo bibliográfico. Rev Rene 2009; 10(4):165-172.

34. Souza LGS, Menandro MCS, Couto LLM, Schimith PB, Lima RP. Saúde Mental na Estratégia Saúde da Família: revisão da literatura brasileira. Saude Soc 2012; 21(4):1022-1034.

35. Paula CS, Lauridsen-Ribeiro E, Wissow L, Bordin IAS, Evans-Lacko S. How to improve the mental health care of children and adolescents in Brazil: Actions needed in the public sector. Rev Bras Psiquiatr 2012; 34(3):1022-1034.

Artigo apresentado em 22/10/2018

Aprovado em 19/11/2019

Versão final apresentada em 21/11/2019

Editores-chefes: Romeu Gomes, Antônio Augusto Moura da Silva 